RUNNING HEAD: Attitudes to Domestic Violence

Development of the Attitudes to Domestic Violence Questionnaire for Children and

Adolescents

\author{
Claire L. Fox ${ }^{\mathrm{a}}$, David Gadd ${ }^{\mathrm{b}}$, \& Julius Sim ${ }^{\mathrm{c}}$ \\ ${ }^{\mathrm{a}}$ Centre for Psychological Research: Keele University, UK; ${ }^{\mathrm{b}}$ School of Law, University of \\ Manchester, UK, ${ }^{\mathrm{C}}$ Centre for Social Policy, Keele University, UK
}

Corresponding author: Dr Claire Fox, School of Psychology, Keele University, Staffs. ST5 5BG, UK. Tel: +44 (0) 1782 733330, Fax: +44 (0) 1782 733387. Email:

c.fox@keele.ac.uk.

Author note

We are grateful to the participating schools, including the teachers that facilitated access and the pupils who completed the questionnaire. Thanks also to the following Research Assistants who helped with the data collection and inputting: Daniel Sayer, Matthew Owen, Randhir Jutley, Rebecca Hale, Catherine Thompson and Danielle Malia. We also gratefully acknowledge the support of the ESRC for a grant that supported study two (RES-062-23-2678) 


\begin{abstract}
In order to provide a more robust assessment of the effectiveness of a domestic abuse prevention education programme, a questionnaire was developed to measure children's attitudes to domestic violence. The aim was to develop a short questionnaire that would be easy to use by practitioners but at the same time sensitive enough to pick up on subtle changes in young people's attitudes. We therefore chose to ask children about different situations in which they might be willing to condone domestic violence. In Study One we tested a set of 20 items, which we reduced by half to a set of ten items. The factor structure of the scale was explored and its internal consistency was calculated. In Study Two, we tested the factor structure of the 10-item Attitudes to Domestic Violence (ADV) scale in a separate calibration sample. Finally, in Study Three we then assessed the test-retest reliability of the 10-item scale. The ADV Questionnaire is a promising tool to evaluate the effectiveness of domestic abuse education prevention programmes. However, further development work is necessary.
\end{abstract}

Keywords: domestic violence, attitudes, questionnaire, psychometric evaluation, prevention 


\section{Development of the Attitudes to Domestic Violence Questionnaire for Children and}

\section{Adolescents}

In the UK, high rates of abuse in teenage dating relationships have been found (Barter, McCarry, Berridge, \& Evans, 2009), highlighting the significance of the issue in the lives of many young people. A recent study of $13-14$ year olds in the UK $(n=1143)$, found that $45 \%$ of pupils who had been in a dating relationship reported having experienced domestic abuse and 25\% reported having perpetrated it (Fox, Corr, Gadd, \& Butler, 2014). Similar rates of abuse have been reported across Europe and North America (see O'Leary \& Smith Slep, 2012 for a recent review). There is, therefore, good reason to target preventative interventions at teenagers in early adolescence.

Domestic abuse prevention education programmes need to begin by engaging with young people's perceptions of abuse. Most young people actually regard hitting a partner as wrong. However, there is evidence that many young people will condone violence in certain circumstances. A survey in Scotland of 14-18 year olds found that there was a low tolerance for violence among teenagers. However, in focus group discussions it became apparent that many were willing to condone violence in certain contexts; for example, 'where a man had been pushed too far' (Burman \& Cartmel, 2005). An earlier survey by Burton, Kitzinger, Kelly and Regan (1998) of 14-21 year olds in Scotland found that 1 in 2 young men and 1 in 3 young women said that it was acceptable for a man to hit a woman in certain circumstances, most notably if a woman had been sexually unfaithful. A consistent finding in the literature is that young men view violence in relationships as more acceptable compared to young women (Burman \& Cartmel, 2005; Burton et al., 1998).

Over the past ten years, a number of domestic abuse prevention education programmes have emerged in the UK. Yet, few have been formally evaluated. Where evaluations have been conducted, they have been small-scale and methodologically limited 
(e.g. Bell \& Stanley, 2005; CRG Research, 2009; Hester \& Westmarland, 2005; Scottish Executive, 2002; Stanley, Ellis, \& Bell, 2011). Rarely are experimental methods used to assess attitudinal or behavioural change. Where questions have been administered at pre-test and post-test, analyses typically involve comparing the percentages of responses to individual items at each time point, with no attempt to track individuals over time, and little consideration of whether the changes are statistically significant.

As noted by Barter (2011), research on what US scholars tend to call 'dating violence' is not as developed in the UK and Europe as in North America. The same is true of attempts to establish effective domestic abuse prevention education programmes. The recent expansion of the UK government's definition of domestic abuse to encompass incidents or patterns of 'controlling, coercive or threatening behaviour' alongside physical assaults, together with its decision to extend this definition from adults to young people aged 16 and over, renders the need to conduct research and evaluation on preventative education all the more urgent. From March 2013:

any incident or pattern of incidents of controlling, coercive, threatening behaviour, violence or abuse between those aged 16 or over who are or have been intimate partners or family members regardless of gender or sexuality

is to be deemed 'domestic violence and abuse' by service providers working within England and Wales (Home Office 2013 p. 2). Consideration is currently being given to extending this definition to include younger teenagers and children too. For consistency, the term 'domestic abuse' will be used in this paper, except when referring to studies which have specifically used the term 'dating violence'. 
Thus, a number of school-based domestic abuse prevention programmes have been developed in the UK, but evidence as to the effectiveness of such programmes is limited. In order to provide a more robust assessment of the effectiveness of one such programme called Relationships without Fear (RwF) delivered by an organization called Arch in North Staffordshire, we developed a questionnaire to measure children's attitudes to domestic violence. The questionnaire was developed in close collaboration with Arch to enable an evaluation of the effectiveness of the RwF programme using a pre-test post-test design. The aim was to create a tool that was easy for practitioners to use and that would be sensitive enough to detect the subtle shift in attitudes to more extreme disapproval of violence. As already noted, most young people regard hitting a partner as wrong. However, many are willing to condone it under certain circumstances. Given that theories of interpersonal aggression highlight the importance of normative beliefs in justifying such actions, it was deemed appropriate to assess attitudes to domestic violence (see Foshee, Linder, MacDougall \& Bangdiwala, 2001). As noted by Huesmann and Guerra (1997), normative beliefs may be related to social norms but need not be consistent with them. They are viewed as "cognitive abstractions of knowledge acquired through observation, experience or direct tuition" (p. 417). In younger children, they are influenced by individual behaviours and other people's reactions to such behaviours. However, once these beliefs are crystallized (at around 9-10 years), they become more resistant to change (Huesmann \& Guerra, 1997). Many learning theories highlight the role of cognition in guiding behaviour across time and in various situations (e.g. Bandura, 1986). Someone who believes that domestic abuse is acceptable will therefore see their actions as valid and/or necessary (Barter et al., 2009). Indeed, studies have found associations between attitudes and behaviour, with young people who are more accepting of violence in relationships being more likely to have perpetrated it (Foshee et al., 2001; O’Keefe, 1998; Sears, Byers, \& Price, 2007). 
In developing this measure we drew inspiration from the Normative Beliefs about Aggression Scale (NOBAGS), developed for US elementary age children (Huesmann \& Guerra, 1997). The NOBAGS has two main sections of questions: one that assesses general beliefs about aggression and another that examines retaliation beliefs about aggression between two children.

There are alternative measures of children's attitudes to violence in relationships, many based on the NOBGAGS. However, information is typically lacking regarding the psychometric properties of these scales. Furthermore, the internal consistency coefficients reported are often below the cut-off point deemed satisfactory, which can limit the conclusions that can be drawn. For example, to evaluate Safe Dates, Foshee et al. (2001) developed four subscales to measure dating violence norms. One subscale was comprised of a single item and two of the subscales were low in terms of internal consistency. The fourth subscale, comprising eight items that measured 'prescribed norms' (based on the NOBAGS), had acceptable internal consistency, with coefficients of .71 and .69 being reported (Foshee et al., 1998; Foshee et al., 2001). A limitation is that of the eight items, only two measure attitudes to female-on-male violence. There is still considerable debate in the literature as to whether domestic abuse remains a crime committed predominantly by men against women or whether 'gender symmetry' is the norm (Archer, 2000; Straus, 2009; Dobash, Dobash, Cavanagh \& Lewis, 1998). However, there is a growing consensus that among teenagers and young adults, incidence rates are similar for boys and girls (Archer, 2000; Moffitt, Caspi, Rutter \& Silva, 2001). Thus, it is imperative that scales designed to capture young people's attitudes reflect their reality. In line with other studies that have found an association between attitudes about the acceptability of violence and perpetration of abuse in relationships, Foshee et al. (2001) found that acceptance of prescribed norms was a predictor of 'dating violence' for males (see also McDonell, Ott, \& Mitchell., 2010; O’Keefe, 1998; Sears et al., 2007). 
Jaycox et al. (2006) developed two new scales from the prescribed norms scale (Foshee et al., 1998) and between-gender items from the retaliation subscale of the NOBAGS. The scale measuring attitudes to male-on-female violence was dropped due to little variability, leaving a 5-item scale measuring female-on-male violence and a four-item scale to measure male-on-female violence after provocation. Yet, information regarding the internal consistency of the subscales is not reported. In a subsequent paper, internal consistency reliability coefficients of .71 and .55 are reported for these two subscales respectively (Orlando Edelen, McCaffrey, Marshall, \& Jaycox, 2009).

A more promising scale is the Attitudes towards Dating Violence (ATDV) questionnaire developed by Price, Byers and the Dating Violence Research Team (1999). This questionnaire comprises 76 items in total with six subscales measuring attitudes towards male and female physical, psychological and sexual abuse. The number of items per subscale varies from 12 to 15 . The six subscales were subjected to factor analysis separately and this identified a single factor solution for each subscale, with all six showing acceptable levels of internal consistency. Boys and girls who scored high on the ATDV were more likely to report having been abusive in past relationships, providing some support for the validity of the scales. There were gender differences, with boys scoring higher than the girls on all six ATDV subscales. However, the temporal stability of the scales still needs to be demonstrated and the utility of the questionnaire is limited by the large number of items.

A scale that bears a strong similarity ${ }^{1}$ to the Attitudes to Domestic Violence (ADV) questionnaire that we developed is the Justification of Violence Scale adapted by O'Keefe (1998) from the Attitudes about Dating Scale developed by Margolin and Foo (1992; see also Foo \& Margolin, 1995). The scale developed by O'Keefe (1998) asks questions about how acceptable it is for a boy to hit or slap a girl and a girl to hit or slap a boy using eight different

\footnotetext{
${ }^{1}$ We came across the article by O'Keefe following the development of the ADV
} 
situations, for example, he/she is drunk/drugged, has been cheated on, made to look foolish. There is a four point response scale whereby respondents have to indicate whether it is never OK (scored 1) to always OK (scored 4). This 16-item scale has acceptable internal consistency, with O'Keefe (1998) reporting a Cronbach's alpha of .89. However, to our knowledge, data are lacking regarding the test-retest reliability of the scale.

In this paper we report on a study to develop the ADV Questionnaire prior to embarking on an evaluation of a domestic abuse prevention education programme. As previously noted we aimed to develop a short questionnaire that would be easy to use by practitioners but at the same time sensitive enough to pick up on subtle changes in young people's attitudes. Like O'Keefe (1998), we therefore chose to ask children about different situations in which they might be willing to condone domestic violence. In Study One we tested a set of 20 items, which we reduced by half to a set of ten items. The factor structure of the scale was explored and its internal consistency was calculated. In Study Two, we tested the factor structure of the 10-item ADV scale in a separate calibration sample. Finally, in Study Three we then assessed the test-retest reliability of the 10-item scale.

\section{Study One}

\section{Method}

Participants. In total, 226 Year 9 pupils (aged 13-14 years) from two UK secondary schools completed the ADV questionnaire in the first session of $\mathrm{RwF}^{2}$ during the school year 2009-2010 (112 male and 113 female, with 1 'missing'). Parental consent was sought using the opt-out method of gaining parental consent. Pupils with parental consent were additionally asked for their own assent to take part in the study as part of the evaluation.

Materials. The ADV was originally piloted as a 20-item questionnaire with questions about the acceptability of violence by a man and a woman using ten different situations (see

\footnotetext{
${ }^{2}$ Pupils also completed the ADV questionnaire in the final session of RwF as part of a pilot evaluation of RwF. These findings informed a second larger-scale study funded by the ESRC. For details see Fox, Corr, Gadd and Sim, 2014).
} 
Table 1). Items were generated through close consultation with RwF workers who had insight into the kinds of situations in which young people tend to justify violence in relationships. Each question is followed by a four-point scale - 1 = it's perfectly OK, 2 = it's sort of OK, 3 = it's sort of wrong, 4 = it's really wrong. Depending on how the question is phrased, the response scale is presented in reverse order (i.e. $1=\mathrm{it}$ 's really wrong, $2=\mathrm{it}$ 's sort of wrong, 3 $=$ it's sort of OK, $4=$ it's perfectly OK). For those questions that begin 'Do you think it is OK...' the scale begins with 'it's perfectly OK'. The other questions that are phrased: 'Suppose [x happened] how wrong...' have the response scale appearing in reverse order, i.e. 'it's really wrong' to 'it's perfectly OK'. This is to counter the tendency of participants to respond the same way to each question without fully processing what they are being asked (known as 'response set bias'). Four pairs of items were reverse-coded so that for all 20 items a high score indicated that participants were agreeing that the situation was acceptable.

Procedure. The research was conducted in line with the ethical guidelines of the British Psychological Society and clearance was gained from the University Ethical Review Panel. All data collection was overseen by a member of the RwF team who read out the standardized instructions, was on hand to answer any questions and who debriefed the children. Participants were encouraged to read through the questions at their own pace. They were asked to complete a front page with their name and were told: 'Before we look at your questionnaire we will take off this front sheet so that your name will not be attached to your questionnaire. We need your name so that we can match up your answers with the answers you give to the same questions at another time'. The children were reassured that their responses would remain confidential. They were also told that they did not have to take part in the research if they did not want to and could stop taking part at any time. Parental consent was sought using the 'opt-out' method, which meant that parents had to send a form back if they did not wish their child to take part. The participants were asked to answer the questions 
in silence, to keep their answers to themselves and not to look at what the person next to them was doing. When all the completed questionnaires had been collected in, the participants were thanked for taking part in the research and the first session of RwF began.

\section{Results}

As a first stage in developing the scale, the 20 items were reviewed in terms of the distribution of scores. An extreme score with little variation indicates that most respondents are agreeing (or disagreeing) with the item, suggesting that the item has a floor or ceiling effect and thus low discrimination, and may appropriately be deleted. Five pairs of items were deleted on this basis, where one or both items in each pair were showing a high percentage endorsement of the most extreme option (see Table 1). These were all items where there appeared to be weak justification for the violence: items 1 and 2 (being angry), 7 and 8 (loves them), 11 and 12 (partner has got on their nerves), 17 and 18 (being drunk), 19 and 20 (has been shouted at). Endorsement of the most unaccepting response category was accordingly high. The remaining ten items were entered into an exploratory factor analysis in Mplus 7.1, with items designated as ordered categorical and using a WLSMV estimator. Only cases with complete data for the items in the scale were used $(n=209)$. Factor solutions from one to three factors were obtained, using orthogonal varimax rotation. Table 2 shows the resulting factor loadings. Eigenvalues for the three factors extracted were 5.34, 1.13 and 0.95, respectively. The root mean square error approximation (RMSEA), the comparative fit index (CFI) and the Tucker Lewis index (TLI) were used as measure of goodness of fit. For the RMSEA, values close to zero (ideally, .05 or smaller) are desirable, while for the CFI and the TLI, values close to unity (ideally, .95 or greater) are desirable (Byrne, 2012). The chi-square

statistic was also calculated. A well-fitting factor solution should have a non-significant $\chi^{2}$ statistic, but the test is sensitive to sample size and in large samples a model with good fit 
may give rise to a significant test (Brown, 2006). Values of these statistics for the factor solutions obtained are shown in Table 2.

Although chi-square difference testing showed statistically significant increases in model fit from the one-factor through to the three-factor solution (data not shown), there are consistently high loadings of the items in the one-factor solution, whereas some items do not load strongly on any one factor in the other solutions. This makes interpretation of the dimensions within a two- or three-factor solution less than straightforward, and suggests that it is justifiable to treat the 10 items as constituting a single summative scale.

The internal consistency of the 10-item scale was evaluated by calculating the Raykov index of composite reliability (Raykov, 1997). A value of internal consistency of .70 or greater is generally regarded as acceptable (Robinson, Shaver, \& Wrightsman, 1991). The obtained coefficient of $.93(95 \%$ CI $.92, .94)$ for the scale indicates a very high level of internal consistency. The Flesch reading ease score for the scale is 82 , which is US grade 7 (12-13 year olds).

\section{Study Two}

The results of the exploratory factors analysis were confirmed in a separate calibration study, using a sample of children aged 13-14 from a study to evaluate the effectiveness of RwF, using a pre- and post-test control group design (Fox, Corr, Gadd and Sim, 2014).

\section{Method}

Participants. A total of 1073 children (527 boys, 546 girls) aged 13-14 years (Year 9) from 13 schools with complete data on the ADV scale were used in the analysis. Pupils in seven schools received the RwF programme during the school year 2010-2011. Each school was matched with a control group school, not yet receiving the programme. Parental consent was sought using the opt-out method of gaining parental consent. Pupils with parental 
consent were additionally asked for their own assent to take part in the study as part of the evaluation.

Materials. As well as completing the 10-item ADV scale, the participants responded to questions about their experiences of domestic abuse, as victims (VDA), perpetrators (PDA) and witnesses (WDA) of abuse in their own homes. We asked the young people to think about 'people you have dated, and past or current boyfriends or girlfriends'. They were then asked to consider the adults who look after them at home, 'e.g. your parents, stepparents, guardians or foster carers' and questions that are about 'things that can happen between two partners in a relationship'. The questions were very similar to those used in the National Society for the Prevention of Cruelty to Children (NSPCC) survey (Barter et al., 2009), with questions assessing physical, sexual and emotional forms of violence (for further details of the questions asked see Fox, Corr, Gadd \& Butler, 2014; Fox, Corr, Gadd \& Sim, 2014). As the data were positively skewed, binary categories to reflect victim status, perpetrator status and being a witness were formed. For victimization and perpetration, they were asked to consider 10 different behaviours in terms of whether each of these had ever happened to them or whether they had ever done it themselves: 'Never', 'Once' or 'More than once'. Participants' responses were combined to yield a score representing their responses across all the questions in that scale. Thus, there were two categories: 'Never' (they had never experienced or perpetrated any of the forms of abuse) or 'Once or More than once' (they had experienced or perpetrated at least one of the forms of abuse). For witnessing abuse there were 8 different behaviours - the same as for the previous sections, but we omitted the questions about sexual abuse. Again, there were two categories: 'Never' and 'Once or more than once'. Given that very few young people reported experiences that had happened 'More than once', the two categories 'Once' and 'More than once' were combined. 
Procedure. Children in the intervention group completed the questionnaires in the first and final session of RwF and at three-month follow-up; children in the control group schools completed the questionnaires at the same time as the children in the matched intervention schools, within at most one week of each other. Baseline responses on the ADV scale were used for the psychometric evaluation.

All data collection was overseen by a member of the research team, who read out the standardized instructions, was on hand to answer any questions, and debriefed the participants. They were encouraged to read through the questions at their own pace. The questionnaire was anonymous and the participants were reassured that their responses would remain confidential. They were also reassured that if they were willing to answer the questions their responses could not be traced back to them as individuals or to their family They were told that they did not have to take part in the research if they did not want to, and could stop taking part at any time. They were asked to answer the questions in silence, to keep their answers to themselves and to not look at what the person next to them was doing. After they had completed the questionnaire, they were debriefed and were pointed to appropriate sources of support.

\section{Results}

Descriptive statistics. Individual item analyses highlighted the kinds of situations in which hitting a partner was deemed more acceptable. Being hit first and having been cheated on were the two circumstances where violence was more likely to be justified (see Table 3) and violence from women to men was viewed as more acceptable than violence perpetrated by men against women. In addition, boys were much more likely than girls to condone violence in relationships; $47.1 \%$ of boys compared to $31.7 \%$ of girls thought that hitting would be OK in at least one of the ten situations listed $\left(\chi^{2}=26.65, d f=1, p<.001 ; n=1095\right)$. Second, 
violence from women to men was regarded as more socially acceptable than violence perpetrated by men against women; $37.8 \%$ of young people reported that it was 'okay' for a woman to hit her partner in at least one of the circumstances listed compared to $23.6 \%$ of young people who thought it was okay for a man to hit his partner $(p<.001)$.

ADV group differences at pre-test. A series of unrelated ANOVAs were conducted to compare the pre-test scores of males and females and those of subgroups based on experiences of domestic abuse: victims/non-victims of domestic abuse (VDA), perpetrators/non-perpetrators of domestic abuse (PDA) and witnesses/non-witnesses of domestic abuse (WDA). The means and standard deviations and results of the ANOVAS can be seen in Table 4. At pre-test, boys scored higher on the ADV compared to girls, indicating attitudes more accepting of domestic violence. In addition, there were differences between the groups based on experiences of abuse with victims, perpetrators and those who had witnesses abuse scoring higher than those not involved. The lack of significant interaction effects suggests that these group differences held for girls and boys.

Factor analysis. A confirmatory factor analysis for the one-factor solution produced the following measures of goodness of fit: RMSEA $=.24, \mathrm{CFI}=.83, \mathrm{TLI}=.79$ (compared with similar values of $.24, .84$ and .79 , respectively, for the original sample). The factor loadings from the calibration sample were also similar to those from the original sample (Table 5). As noted previously, although the goodness of fit statistics could be deemed unsatisfactory, the consistently high loadings of the items in the one-factor solution warrant their use as a single summative scale.

Configural invariance by gender - i.e. the extent to which the pattern of factor loadings is equivalent for boys and girls - was also tested. To achieve this, we compared two models. The first model was an unconstrained model in which all factor loadings were allowed to vary across boys and girls. The second model constrained the factor loadings to be 
equal across boys and girls. If the fit of the constrained model is significantly worse than that of the unconstrained model, using change in chi-square $\left(\Delta \chi^{2}\right)$ as an indicator, then we can conclude that the pattern of loadings differs across these groups. This test was significant $\left(\chi^{2}\right.$ $=2316.97, d f=70, p<.001)$, suggesting that configural invariance was not present. However, this test is sensitive to sample size, and inspection of Table 5 suggests that the loadings did not differ greatly between boys and girls (the mean absolute difference in loadings is .09; range 0 to .16).

\section{Study Three}

\section{Method}

Participants. In total, 112 children aged $13-15$ years (mean age $=13.83, \mathrm{SD}=0.70)$ from one UK secondary school participated in the study conducted during the school year 2010-2011 (47\% female). Parental consent was sought using the opt-out method of gaining parental consent.

Materials/Procedure. The participants completed the ADV scale on two occasions, two weeks apart. All data collection was overseen by a member of the research team using the same in-class procedures that had been utilized in the two previous studies. This study was not part of a wider evaluation of the RwF programme.

\section{Results}

The test-retest agreement of the scale was tested by calculating an intraclass correlation coefficient $\left(\mathrm{ICC}_{2,1}\right)$. This gave an ICC of .72 (95\% CI .61, .80); this was significantly larger than a null value of $.60(p=.015)$, the lower boundary for 'moderate' reliability according to Shrout's (1998) benchmarks. 


\section{Discussion}

As previously noted, a number of school-based domestic abuse prevention programmes have been developed in the UK, but evidence as to the effectiveness of such programmes is limited. In order to provide a more robust assessment of the effectiveness of one such programme, we developed a questionnaire to measure children's attitudes to domestic violence. Over the course of three studies, the 10-item ADV Questionnaire was developed. Although the measures of goodness of fit from the factor analysis are lower than the ideal benchmarks, the consistently high loadings of all items on a single factor suggest that the scale can be used as a single summative index. In addition, the scale demonstrates good internal consistency and reproducibility over time; the coefficients obtained were both notably higher than recommended thresholds (Robinson, Shaver, \& Wrightsman, 1991; Shrout, 1998). This questionnaire shows great promise in providing educators with a quick and easy tool with which to evaluate the effectiveness of domestic abuse prevention programmes. Previous measures have suffered from limitations in terms of low levels of internal consistency, length/utility, and/or lack of data on the test-retest reliability of these scales.

In line with previous studies we found that boys were more accepting of domestic violence compared to girls and there were also differences based on experiences of abuse, with victims, perpetrators and those who had witnessed abuse showing a greater acceptance of violence in relationships in comparison to those not currently involved. These data provide some validation data in support of the ADV, due to previous studies having found an association between attitudes and self-reported behaviour (e.g. Foshee et al., 2001; O'Keefe, 1998; Sears, Byers, \& Price, 2007).

In line with previous studies (e.g. Burman \& Cartmel, 2005; Burton et al., 1998), boys were more accepting than girls of domestic violence. In addition, female-on-male violence 
was deemed more acceptable than male-on-female violence (Price et al., 1999). The findings are explained in terms of social norms about male and female behaviour - women are perceived as weak and vulnerable (Gerber, 1991), whereas men are viewed as strong and assertive (Askew, 1989; Burr, 1998).

The situations in which young people were more willing to condone such violence were if there had been physical provocation and if they had been cheated on. We would argue that this needs to be the starting point with young people in education programmes. Most young people know that hitting a partner is wrong; however, many are willing to condone it in certain circumstances. An experienced educator can facilitate discussion of issues around trust, betrayal, intimacy and handling conflict to help young people see that there are alternative ways of responding.

The ADV has been shown to be a reliable tool, sensitive enough to detect changes in young people's attitudes (Fox, Corr, Gadd, \& Sim, 2014). This is despite the well-known 'floor effect', which means that it is often difficult to detect a shift in children's attitudes towards more extreme disapproval of violence. Previous evaluations have failed to demonstrate change in attitudes, possibly because the measures were not sensitive enough to detect these subtle changes (Avery-Leaf, Cascardi, O’Leary, \& Cano, 1997). We believe this was achieved by basing the questionnaire on the NOBAGS (Huesmann \& Guerra, 1997), which assesses retaliatory beliefs to aggression. As noted in the Introduction, studies typically find that there is a low tolerance for violence among teenagers. However, in focus group discussions it becomes apparent that many young people are willing to condone violence in certain contexts (Burman \& Cartmel, 2005). However, further validation work would be beneficial, perhaps with the inclusion of additional items that tap into attitudes towards abuse in same-sex relationships. 
There are many good reasons for targeting preventative interventions at teenagers in early adolescence. As indicated, high rates of abuse have been identified at this age. In addition, preventative work is more cost-effective, when we consider the costs to society in terms of social care, health care and the criminal justice system. However, we need to consider how best to deliver effective domestic abuse prevention education. Such programmes must be theoretically informed but also evidence-based. Unfortunately, research on 'dating violence' in the UK and elsewhere in Europe has lagged behind that conducted in North America and the same is true of attempts to establish effective domestic abuse prevention education programmes (Barter, 2011). Even in the US, the evidence in support of such programmes has its limitations, which diminishes the conclusions that can be drawn, as noted by Whitaker et al. (2006): "Domestic violence prevention programs are a promising approach to the prevention of partner violence but we submit that more data are needed to make stronger conclusions" (p. 160). They further note that evaluations are often hampered by the lack of standardized instruments; typically measures that have been developed for adults are then adapted for use with children. However, the reliability and validity of such instruments has not been well researched. In conclusion, we would argue that the ADV questionnaire shows great promise for use in evaluations of domestic abuse prevention programmes to enable those in the field to build up the evidence based in the UK and elsewhere. However, further development work is necessary. 


\section{References}

Archer, J. (2000). Sex differences in aggression between heterosexual partners: A metaanalytic review. Psychological Bulletin, 126, 651-680.

Askew, S. (1989). Aggressive behaviour in boys: To what extent is it institutionalised? In D. P. Tattum, \& D. L. Lane (Eds.), Bullying in schools (pp. 59-72). Stoke-on-Trent: Trentham Books.

Avery-Leaf, S., Cascardi, M., O’Leary, K. D., \& Cano, A. (1997). Efficacy of a dating violence prevention program on attitudes justifying aggression. Journal of Adolescent Health, 21, 11-17.

Bandura, A. (1986). Social foundations of thought and action: A social cognitive theory. Englewood Cliffs NJ: Prentice Hall.

Barter, C. (2011). A thoroughly gendered affair: teenage partner violence and exploitation. In C. Barter \& D. Berridge (Eds.), Children behaving badly? Peer violence between children and young people (pp. 103-120). West Sussex: Wiley-Blackwell.

Barter, C., McCarry, M., Berridge, D., \& Evans, K. (2009). Partner exploitation and violence in teenage intimate relationships. London: NSPCC.

Bell. J., \& Stanley, N. (2005). Tackling domestic violence at the local level: An evaluation of the Preston Road domestic violence project. Hull: University of Hull.

Brown, T. A. (2006). Confirmatory factor analysis for applied research. New York: Guilford Press.

Burman, M., \& Cartmel, F. (2005). Young people's attitudes towards gendered violence. Edinburgh: NHS Scotland.

Burr, V. (1998). Gender and social psychology. London: Routledge.

Burton, S., Kitzinger, J. Kelly, L., \& Regan, L. (1998). Young people's attitudes towards violence, sex and relationships. Edinburgh: Zero Tolerance Charitable Trust. 
Byrne, B. M. (2012). Structural equation modeling with Mplus: basic concepts, applications and programming. New York: Routledge.

CRG Research (2009). An independent evaluation of the Trust Education Project: Final Report. London: Tender.

Dobash, R. E., Dobash, R. P., Cavanagh, K., \& Lewis, R. (1998). Separate and intersecting realities: A comparison of men's and women's accounts of violence against women. Violence against Women, 4, 382, 414.

Foo, L., \& Margolin, G. (1995). A multivariate investigation of dating violence. Journal of Family Violence, 10, 351-375.

Foshee, V. A., Bauman, K. E., Arriaga, X. B., Helms, R. W., Koch, G. G., \& Linder, G. F. (1998). An evaluation of Safe Dates, an adolescent dating violence prevention program. American Journal of Public Health, 88, 45-50.

Foshee, V. A., Linder, G. F., MacDougall, J., \& Bangdiwala, S. (2001). Gender differences in the longitudinal predictors of adolescent dating violence. Preventive Medicine, 32, $128-141$.

Fox, C. L., Corr, M-L., Gadd, D., \& Butler, I., (2014). Young teenagers' experiences of domestic abuse. Journal of Youth Studies, 17, 510-526.

Fox, C. L., Corr, M-L., Gadd, D., \& Sim. J. (2014). Evaluating the effectiveness of domestic abuse prevention education. Legal and Criminological Psychology, DOI: $10.1111 /$ lcrp. 12046

Gerber, G. L. (1991). Gender stereotypes and power: Perceptions of the roles in violent marriages. Sex Roles, 24, 439-258.

Hester, M., \& Westmarland, N. (2005). Tackling domestic violence: Effective interventions and approaches. London: Home Office.

Home Office (2013). Information for local areas on the change to the definition of domestic 
violence and abuse. HM Government: Home Office.

Huesmann, L. R., \& Guerra, N. G. (1997). Normative beliefs and the development of aggressive behavior. Journal of Personality and Social Psychology, 72, 408-419.

Jaycox, L. H., McCaffrey, D., Eiseman, B., Aronoff, J., Shelley, G. A., Collins, R. L., \& Marshall, G. N. (2006). Impact of a schools-based dating violence prevention program among Latino teens: Randomized controlled effectiveness trial. Journal of Adolescent Health, 39, 694-704.

Margolin, G., \& Foo, L. (1992). The attitudes about dating scale. An unpublished measure. University of Southern California.

McDonell, J., Ott, J., \& Mitchell, M. (2010). Predicting dating violence and perpetration among middle and high school students in a rural southern community. Children and Youth Services Review, 32, 1458-1463.

Moffitt, T., Caspi, K., Cavanagh, K., \& Lewis, R. (2001). Sex differences in antisocial behaviour: Conduct disorder, delinquency, and violence in the Dunedin longitudinal study. Cambridge: Cambridge University Press.

O’Keefe, M. (1998). Factors mediating the link between witnessing interparental violence and dating violence. Journal of Family Violence, 13, 39-57.

O’Leary, K. D., \& Smith-Slep, A. M. (2012). Prevention of partner violence by focusing on behaviors of both young males and females. Prevention Science, 13, 329-339.

Orlando Edelen, M., McCaffrey, D., Marshall, G. N., \& Jaycox, L. H. (2009). Measurement of teen dating violence attitudes: An item response theory evaluation of differential item functioning according to gender. Journal of Interpersonal Violence, 24, 12431263.

Price, E. L., Byers, E. S., \& the Dating Violence Research Team (1999). The Attitudes 
towards Dating Violence scales: Development and initial validation. Journal of Family Violence, 14, 351-575.

Raykov, T. (1997). Estimation of composite reliability for congeneric measures. Applied Psychological Measurement, 21, 173-184

Robinson, J. P., Shaver, P. R., \& Wrightsman, L. S. (1991). Criteria for scale selection and evaluation. In J. P. Robinson, P. R. Shaver, \& L. S. Wrightsman (Eds.), Measures of Personality and Social Psychological Attitudes (pp. 1-16). New York: Academic Press.

Scottish Executive (2002). Evaluation of the zero tolerance 'respect' pilot project. Edinburgh: Scottish Executive.

Sears, H. A., Byers, E. S., \& Price, E. L. (2007). The co-occurrence of boys' and girls' use of psychologically, physically and sexually abusive behaviours in their dating relationships. Journal of Adolescence, 30, 487-504.

Shrout, P. E. (1998). Measurement reliability and agreement in psychiatry. Statistical Methods in Medical Research 7, 301-317.

Stanley, N., Ellis, J., \& Bell, J. (2011). Delivering preventive programmes in schools: Identifying gender issues. In C. Barter \& D. Berridge (Eds.), Children behaving badly? Peer violence between children and young people (pp. 217-230). London: John Wiley and Sons.

Straus, M. (2009). Gender symmetry in partner violence: evidence and implications for prevention and treatment. In: D. G. Whitaker \& J. R. Lutzker (Eds.), Preventing partner violence: Research and evidence-based intervention strategies (pp. 245-271). Washington DC: American Psychological Association.

Whitaker, D. J., Morrison, S., Lindquist, C., Hawkins, S. R., O’Neil, J. A., Nesius, A. M., Mathew, A., \& Reese, L., (2006). A critical review of interventions for the primary 
prevention of perpetration of partner violence. Aggression and Violent Behavior, 11, 151-166. 
Table 1

Attitudes to Domestic Violence Questionnaire items: Percentage endorsement of the most extreme response category and polychoric item-total correlations

\begin{tabular}{|c|c|c|}
\hline Items & $\begin{array}{c}\% \\
\text { endorsement }\end{array}$ & $\begin{array}{l}\text { Item-total } \\
\text { correlation }\end{array}$ \\
\hline $\begin{array}{l}\text { 1) Suppose a man is angry with his partner/wife, do you think } \\
\text { it is wrong for HIM }{ }^{\mathrm{a}} \text { to hit HER? }\end{array}$ & 85 & .655 \\
\hline $\begin{array}{l}\text { 2) Suppose a woman is angry with her partner/husband, do } \\
\text { you think it is wrong for HER to hit HIM? }\end{array}$ & 54 & .560 \\
\hline $\begin{array}{l}\text { 3) Do you think it is OK for a man to hit his partner/wife if } \\
\text { HE says he is sorry afterwards? }\end{array}$ & 62 & .671 \\
\hline $\begin{array}{l}\text { 4) Do you think it is OK for a woman to hit her } \\
\text { partner/husband if SHE says she is sorry afterwards? }\end{array}$ & 47 & .608 \\
\hline $\begin{array}{l}\text { 5) Suppose a woman cheats on her partner/husband with } \\
\text { another man, do you think it is wrong for HIM to hit HER? }\end{array}$ & 51 & .648 \\
\hline $\begin{array}{l}\text { 6) Suppose a man cheats on his partner/wife with another } \\
\text { woman, do you think it is wrong for HER to hit HIM? }\end{array}$ & 39 & .641 \\
\hline $\begin{array}{l}\text { 7) Do you think it is OK for a man to hit his partner/wife if } \\
\text { HE loves HER? }\end{array}$ & 85 & .603 \\
\hline $\begin{array}{l}\text { 8) Do you think it is OK for a woman to hit her } \\
\text { partner/husband if SHE loves HIM? }\end{array}$ & 78 & .657 \\
\hline $\begin{array}{l}\text { 9) Suppose a woman really embarrasses her partner/husband, } \\
\text { do you think it is wrong for HIM to hit HER? }\end{array}$ & 69 & .686 \\
\hline $\begin{array}{l}\text { 10) Suppose a man really embarrasses his partner/wife, do } \\
\text { you think it is wrong for HER to hit HIM? }\end{array}$ & 61 & .743 \\
\hline $\begin{array}{l}\text { 11) Suppose a woman gets on her partner/husband's nerves, } \\
\text { do you think it is wrong for HIM to hit HER? }\end{array}$ & 78 & .779 \\
\hline $\begin{array}{l}\text { 12) Suppose a man gets on his partner/wife's nerves, do you } \\
\text { think it is wrong for HER to hit HIM? }\end{array}$ & 68 & .757 \\
\hline $\begin{array}{l}\text { 13) Do you think it is OK for a man to hit his partner/wife if } \\
\text { HE thinks SHE deserves it? }\end{array}$ & 67 & 699 \\
\hline $\begin{array}{l}\text { 14) Do you think it is OK for a woman to hit her } \\
\text { partner/husband if SHE thinks HE deserves it? }\end{array}$ & 55 & .757 \\
\hline $\begin{array}{l}\text { 15) Suppose a woman hits her partner/husband, do you think } \\
\text { it is wrong for HIM to hit HER? }\end{array}$ & 47 & .660 \\
\hline $\begin{array}{l}\text { 16) Suppose a man hits his partner/wife, do you think it is } \\
\text { wrong for HER to hit HIM? }\end{array}$ & 35 & .656 \\
\hline $\begin{array}{l}\text { 17) Do you think it is OK for a man to hit his partner/wife if } \\
\text { HE is drunk? }\end{array}$ & 77 & .579 \\
\hline $\begin{array}{l}\text { 18) Do you think it is OK for a woman to hit her } \\
\text { partner/husband if SHE is drunk? }\end{array}$ & 73 & .636 \\
\hline $\begin{array}{l}\text { 19) Suppose a woman shouts at her partner/husband, do you } \\
\text { think it is wrong for HIM to hit HER? }\end{array}$ & 75 & .755 \\
\hline $\begin{array}{l}\text { 20) Suppose a man shouts at his partner/wife, do you think it } \\
\text { is wrong for HER to hit HIM? }\end{array}$ & 69 & .728 \\
\hline
\end{tabular}

${ }^{\mathrm{a}}$ The items are formatted as they appear on the questionnaire 
Table 2

Attitudes towards Domestic Violence Questionnaire items (10-item version): Factor loadings

\begin{tabular}{|c|c|c|c|c|c|c|}
\hline \multirow[b]{2}{*}{ Items } & \multicolumn{6}{|c|}{ Solutions } \\
\hline & \multirow{2}{*}{$\begin{array}{c}\begin{array}{c}1 \\
\text { factor }\end{array} \\
.77^{*}\end{array}$} & \multicolumn{2}{|c|}{$\begin{array}{c}2 \\
\text { factors }\end{array}$} & \multicolumn{3}{|c|}{$\begin{array}{c}3 \\
\text { factors }\end{array}$} \\
\hline 1(3) Do you think it is OK for a man to hit his partner/wife if HE says he is sorry afterwards? & & $.91^{*}$ & $.10^{*}$ & $.90^{*}$ & .07 & $.34 *$ \\
\hline 2(4) Do you think it is OK for a woman to hit her partner/husband if SHE says she is sorry afterwards? & $.70^{*}$ & $.76^{*}$ & $.15^{*}$ & $.69^{*}$ & $.16^{*}$ & $.30^{*}$ \\
\hline $\begin{array}{l}\text { 3(5) Suppose a woman cheats on her partner/husband with another man, do you think it is wrong for HIM } \\
\text { to hit HER? }\end{array}$ & $.76^{*}$ & $.18^{*}$ & $.80 *$ & .13 & $.74 *$ & $.32 *$ \\
\hline $\begin{array}{l}\text { 4(6) Suppose a man cheats on his partner/wife with another woman, do you think it is wrong for HER to } \\
\text { hit HIM? }\end{array}$ & $.76^{*}$ & $.13^{*}$ & $.88 *$ & .07 & $.86^{*}$ & $.30^{*}$ \\
\hline $\begin{array}{l}\text { 5(9) Suppose a woman really embarrasses her partner/husband, do you think it is wrong for HIM to hit } \\
\text { HER? }\end{array}$ & $.73^{*}$ & $.53 *$ & $.52 *$ & $.57 *$ & $.58^{*}$ & .07 \\
\hline 6(10) Suppose a man really embarrasses his partner/wife, do you think it is wrong for HER to hit HIM? & $.76^{*}$ & $.55^{*}$ & $.55^{*}$ & $.59 *$ & $.64^{*}$ & .10 \\
\hline 7(13) Do you think it is OK for a man to hit his partner/wife if HE thinks SHE deserves it? & $.81^{*}$ & $.69^{*}$ & $.47 *$ & $.28^{*}$ & $.17^{*}$ & $.87 *$ \\
\hline 8(14) Do you think it is OK for a woman to hit her partner/husband if SHE thinks HE deserves it? & $.82 *$ & $.67^{*}$ & $.50 *$ & $.30^{*}$ & $.28 *$ & $.76^{*}$ \\
\hline 9(15) Suppose a woman hits her partner/husband, do you think it is wrong for HIM to hit HER? & $.73^{*}$ & $.45^{*}$ & $.60 *$ & $.25^{*}$ & $.43^{*}$ & $.60^{*}$ \\
\hline 10(16) Suppose a man hits his partner/wife, do you think it is wrong for HER to hit HIM? & $.70^{*}$ & $.37 *$ & $.63^{*}$ & $.16^{*}$ & $.47^{*}$ & $.56^{*}$ \\
\hline RMSEA & .24 & \multicolumn{2}{|c|}{.23} & \multicolumn{3}{|c|}{.22} \\
\hline CFI & .84 & \multicolumn{2}{|c|}{.89} & \multicolumn{3}{|c|}{.92} \\
\hline TLI & .79 & \multicolumn{2}{|c|}{.81} & \multicolumn{3}{|c|}{.81} \\
\hline$\chi^{2}$ & 435.91 & \multicolumn{2}{|c|}{300.52} & \multicolumn{3}{|c|}{206.67} \\
\hline$d f$ & 35 & \multicolumn{2}{|c|}{26} & \multicolumn{3}{|c|}{18} \\
\hline$p$ value & $<.001$ & \multicolumn{2}{|c|}{$<.001$} & \multicolumn{3}{|c|}{$<.001$} \\
\hline
\end{tabular}

Items have been renumbered; original item numbers from the 20 -item version are given in parentheses

Asterisks indicate loadings that are statistically significant at $p \leq .05$. 
Table 3

$\%$ of children and young people that thought it was 'OK' for a man/woman to hit his/her partner for the different conditions: Pre-Test by gender

Overall Boys Girls

$(\%) \quad(\%) \quad(\%)$

\begin{tabular}{llll}
\hline OK for a man to hit his partner/wife if he says he is sorry afterwards $\quad 3.8 \%$ & $4.3 \%$ & $3.4 \%$
\end{tabular}

OK for a woman to hit her partner/husband if she says she is sorry $\quad 6.5 \% \quad 8.3 \% \quad 4.9 \%$

afterwards

OK for a man to hit his partner/wife if she cheats on him

$8.7 \% \quad 10.2 \% \quad 6.9 \%$

OK for a woman to hit her partner/husband if he cheats on her

$14.5 \% \quad 17.4 \% \quad 11.5 \%$

OK for a man to hit his partner/wife if she really embarrasses him

$3.4 \% \quad 4.1 \% \quad 2.8 \%$

OK for a woman to hit her partner/husband if he really embarrasses

$5.9 \% \quad 7.6 \% \quad 3.9 \%$

her

OK for a man to hit his partner/wife if he thinks she deserves it

$4.8 \% \quad 6.3 \% \quad 3.4 \%$

OK for a woman to hit her partner/husband if she thinks he deserves

$7.3 \%$

$9.1 \% \quad 4.8 \%$

it

OK for a man to hit his partner/wife if she hits him

$13.6 \% \quad 18.2 \% \quad 9.6 \%$

OK for a woman to hit her partner/husband if he hits her

$24.4 \% \quad 30.5 \% \quad 18.4 \%$ 
Table 4

Pre-test means (SDs) and comparisons of the Attitudes to Domestic Violence Questionnaire by gender and experiences of domestic abuse

\begin{tabular}{|c|c|c|c|c|}
\hline & \multicolumn{3}{|c|}{$\operatorname{Mean}(S D)$} & \multirow[t]{2}{*}{$p$ values } \\
\hline & Girls & Boys & Overall & \\
\hline \multicolumn{5}{|l|}{ Victimization } \\
\hline Victims & $1.41(0.40)$ & $1.55(0.41)$ & $1.48(0.41)$ & Gender: $F_{1,1067}=18.91^{\dagger \dagger \dagger}$ \\
\hline Non-victims & $1.39(0.37)$ & $1.47(0.45)$ & $1.43(0.42)$ & Victimization: $F_{1,1067}=4.06^{\dagger}$ \\
\hline Overall & $1.39(0.38)$ & $1.50(0.44)$ & & Gender*Victim: $F_{1,1067}=1.39$ \\
\hline \multicolumn{5}{|l|}{ Perpetration } \\
\hline Perpetrators & $1.49(0.45)$ & $1.58(0.41)$ & $1.53(0.44)$ & Gender: $F_{1,1057}=10.32^{\dagger \dagger}$ \\
\hline Non-perpetrators & $1.37(0.36)$ & $1.48(0.44)$ & $1.43(0.40)$ & Perpetration: $F_{1,1057}=13.26^{\dagger \dagger \dagger}$ \\
\hline Overall & $1.40(0.38)$ & $1.50(0.43)$ & & Gender*Perpet: $F_{1,1057}=0.04$ \\
\hline \multicolumn{5}{|l|}{ Witnessing } \\
\hline Witnesses & $1.46(0.40)$ & $1.54(0.43)$ & $1.49(0.41)$ & Gender: $F_{1,1043}=13.53^{\dagger \dagger \dagger}$ \\
\hline Non-witnesses & $1.36(0.36)$ & $1.47(0.44)$ & $1.42(0.41)$ & Witness: $F_{1,1043}=9.18^{\dagger}$ \\
\hline Overall & $1.40(0.38)$ & $1.49(0.44)$ & & Gender*Witness: $F_{1,1043}=0.27$ \\
\hline
\end{tabular}


Table 5

Attitudes towards Domestic Violence Questionnaire items (10 in total): Comparison of factor loadings between the original and the calibration dataset.

\begin{tabular}{|c|c|c|c|c|}
\hline \multirow[b]{2}{*}{ Items } & \multirow{2}{*}{$\begin{array}{l}\text { Original } \\
\text { dataset }\end{array}$} & \multicolumn{3}{|c|}{ Calibration dataset } \\
\hline & & Overall & Boys & Girls \\
\hline $\begin{array}{l}\text { 1(3) Do you think it is OK for a man to hit his partner/wife if } \\
\text { HE says he is sorry afterwards? }\end{array}$ & .77 & .81 & .77 & .90 \\
\hline $\begin{array}{l}\text { 2(4) Do you think it is OK for a woman to hit her } \\
\text { partner/husband if SHE says she is sorry afterwards? }\end{array}$ & .70 & .78 & .74 & .88 \\
\hline $\begin{array}{l}\text { 3(5) Suppose a woman cheats on her partner/husband with } \\
\text { another man, do you think it is wrong for HIM to hit HER? }\end{array}$ & .76 & .81 & .79 & .86 \\
\hline $\begin{array}{l}\text { 4(6) Suppose a man cheats on his partner/wife with another } \\
\text { woman, do you think it is wrong for HER to hit HIM? }\end{array}$ & .76 & .79 & .75 & .87 \\
\hline $\begin{array}{l}\text { 5(9) Suppose a woman really embarrasses her } \\
\text { partner/husband, do you think it is wrong for HIM to hit HER? }\end{array}$ & .73 & .69 & .69 & .67 \\
\hline $\begin{array}{l}\text { 6(10) Suppose a man really embarrasses his partner/wife, do } \\
\text { you think it is wrong for HER to hit HIM? }\end{array}$ & .76 & .68 & .70 & .64 \\
\hline $\begin{array}{l}\text { 7(13) Do you think it is OK for a man to hit his partner/wife if } \\
\text { HE thinks SHE deserves it? }\end{array}$ & .81 & .84 & .80 & .95 \\
\hline $\begin{array}{l}8(14) \text { Do you think it is OK for a woman to hit her } \\
\text { partner/husband if SHE thinks HE deserves it? }\end{array}$ & .82 & .82 & .77 & .93 \\
\hline $\begin{array}{l}\text { 9(15) Suppose a woman hits her partner/husband, do you think } \\
\text { it is wrong for HIM to hit HER? }\end{array}$ & .73 & .69 & .71 & .66 \\
\hline $\begin{array}{l}\text { 10(16) Suppose a man hits his partner/wife, do you think it is } \\
\text { wrong for HER to hit HIM? }\end{array}$ & .70 & .69 & .68 & .68 \\
\hline
\end{tabular}

Items have been renumbered; original item numbers from the original 20-item scale are given in parentheses. 